Brit. Heart J., 1965, 27, 604.

\title{
RADIOLOGICAL AND SURGICAL ANATOMY IN TETRALOGY OF FALLOT AND THE EFFECT ON SURGICAL PROGNOSIS
}

\author{
BY
}

\author{
D. R. SMITH, H. EFFAT, M. A. HAMED, AND M. AL OMERI
}

From the Departments of Medicine (Clinical Cardiology), Radiology, and Surgery, Postgraduate Medical School, London

Received November 24, 1964

The tetralogy of Fallot constitutes the commonest variety of cyanotic congenital heart disease found in patients surviving infancy (Wood, 1956; Keith, Rowe, and Vlad, 1958). Following the pioneer work of Lillehei and his associates (1955), the complete surgical correction of this lesion has become a standard procedure in most centres. Although Malm et al. (1963) have reported 41 consecutive patients undergoing surgery with no immediate operative mortality, other series indicate that an appreciable hazard remains when attempting complete correction (Table I). Although the

TABLE I

Mortality of Complete Correction in the Tetralogy of Fallot

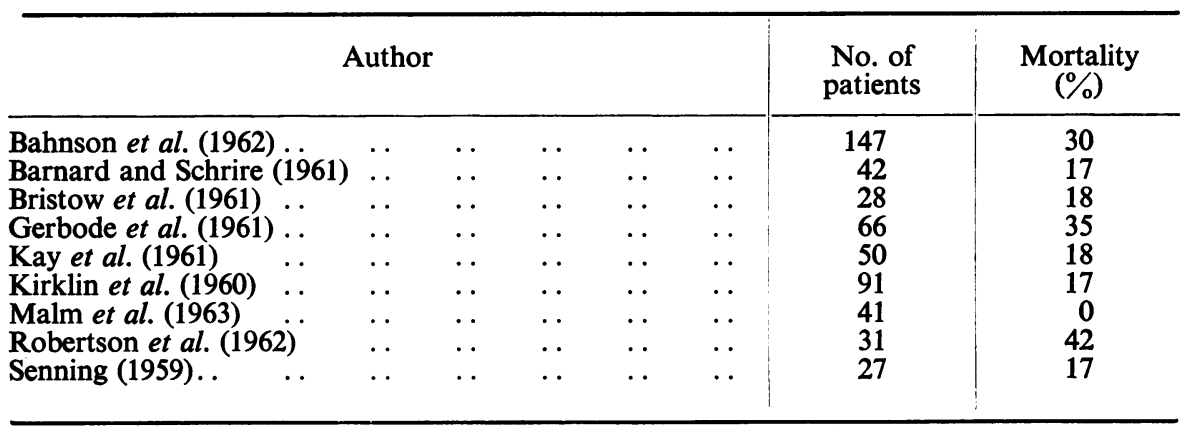

disordered physiology occurring in this form of cyanotic heart disease influences the death rate after operation, it is evident that an accurate assessment of the abnormal intracardiac anatomy will be helpful to the surgeon and may be of some assistance in deciding the operative prognosis of any particular patient. A selective right ventricular angiocardiogram provides the best method of displaying the intracardiac anatomy, and is, in any event, necessary to exclude those patients with double outlet right ventricle with pulmonary stenosis (Neufeld, DuShane, and Edwards, 1961), or corrected transposition with pulmonary stenosis (Morgan et al., 1962) who may masquerade clinically as the tetralogy of Fallot.

Although the angiocardiographic appearances of the tetralogy of Fallot have been well documented in the past (Kjellberg et al., 1959; Vogelpoel et al., 1957; Coelho et al., 1961) (a typical example is shown in Fig. 1), little attention has been paid to the correlation of the radiological appearances with those subsequently found at open-heart surgery. The present study attempts to compare the angiocardiographic appearances with the surgeon's description of the abnormalities found at operation, and, where possible, to indicate those points which may be of prognostic importance. 


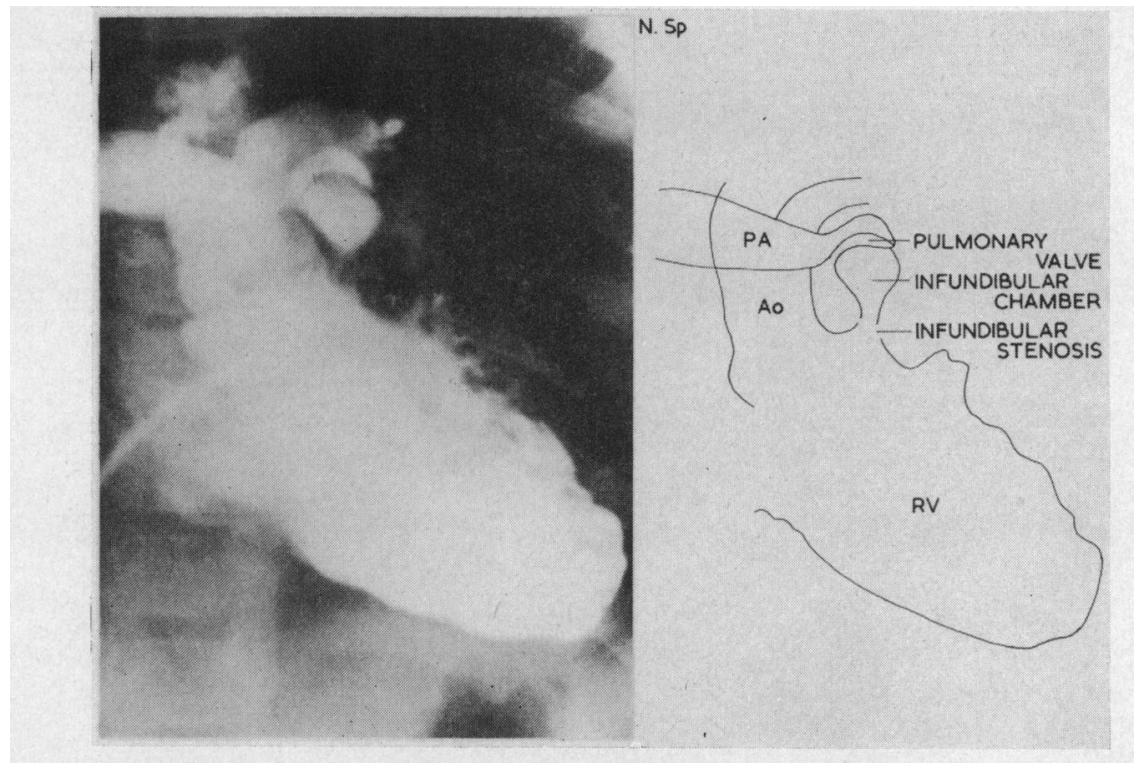

FIG. 1.-Antero-posterior view. Right ventricular injection. Typical appearances of the tetralogy of Fallot: domed pulmonary valve; localized infundibular narrowing with formation of an infundibular chamber. Simultaneous opacification of aorta and main pulmonary artery $(\mathbf{P A}=$ pulmonary artery, $\mathrm{RV}=$ right ventricle, $\mathrm{Ao}=$ aorta).

\section{SuBJeCTS AND Methods}

Patients with the tetralogy of Fallot are defined in this unit as having a ventricular septal defect with obstruction to right ventricular outflow resulting in arterial desaturation which is always present on exertion and usually present at rest. All patients in the present series fell within the scope of this definition. Only those patients subsequently undergoing complete correction are included in this study. Patients undergoing palliative operations such as closed infundibular resection (Brock) or the Blalock anastomosis were excluded as the procedure did not permit visualization of the ventricular cavity.

Selective right ventricular angiocardiography was carried out in every case, the saphenous route being preferred when possible and the catheter advanced as far as possible down towards the apex of the right ventricle, ensuring complete filling of this chamber with contrast material. Films were taken with ElemaSchonander biplane equipment; initially cut-film was used but latterly roll-film. The programme found most satisfactory in the tetralogy was 6 exposures per second for 2 seconds, followed by 3 exposures per second for a further 4-6 seconds. Hypaque, 85 per cent, was used almost exclusively as the contrast material of choice, this being given in a dosage of up to $1.5 \mathrm{ml}$. per $\mathrm{kg}$. body weight.

The angiocardiograms of 50 patients were studied and analysed for the following features. (1) The site and size of the ventricular septal defect. (2) The calibre of the aorta and main pulmonary artery. (3) The site and nature of the right ventricular outflow tract obstruction, including, where possible, an assessment of the size of the pulmonary valve ring. (4) The degree of aortic override. (5) The size of the left atrium.

The data obtained from this analysis were then compared with those available from the operative records subsequently made at the time of complete correction by Mr. W. P. Cleland or Mr. H. H. Bentall using cardiopulmonary bypass under the direction of Dr. Denis Melrose. Being a retrospective study, data were sometimes lacking in the operative records concerning particular points, but operative data have been included in this report only if an unequivocal statement was entered in the notes at the time of the operation.

Ventricular Septal Defect. The early films in the lateral projection were found to be of most value in estimating the size of the ventricular septal defect. In this projection contrast material can be seen streaming through the defect into the aorta, or alternatively spilling over into the left ventricle and outlining the aortic cusps. A single film may give a false impression, but by a study of several successive frames it is usually possible to decide the limits of the ventricular septal defect with a substantial amount of confidence (Fig. 2A and B). The position of the septal cusp of the tricuspid valve should be noted with care, as in the majority 
FIG. 2.-A. Lateral view, right ventricular injection. Note contrast streaming across the ventricular septal defect and entering the aorta. The streaming may indicate the margins of the ventricular septal defect, but does not suggest that the aorta is anteriorly placed. In this case the pulmonary artery can be seen faintly opacified anterior to the aorta.

B. Lateral view, right ventricular injection. Arrows indicate the aortic cusps and the septal cusp of the tricuspid valve. Ventricular septal defect will lie between these points $(\mathrm{LV}=$ left ventricle). 


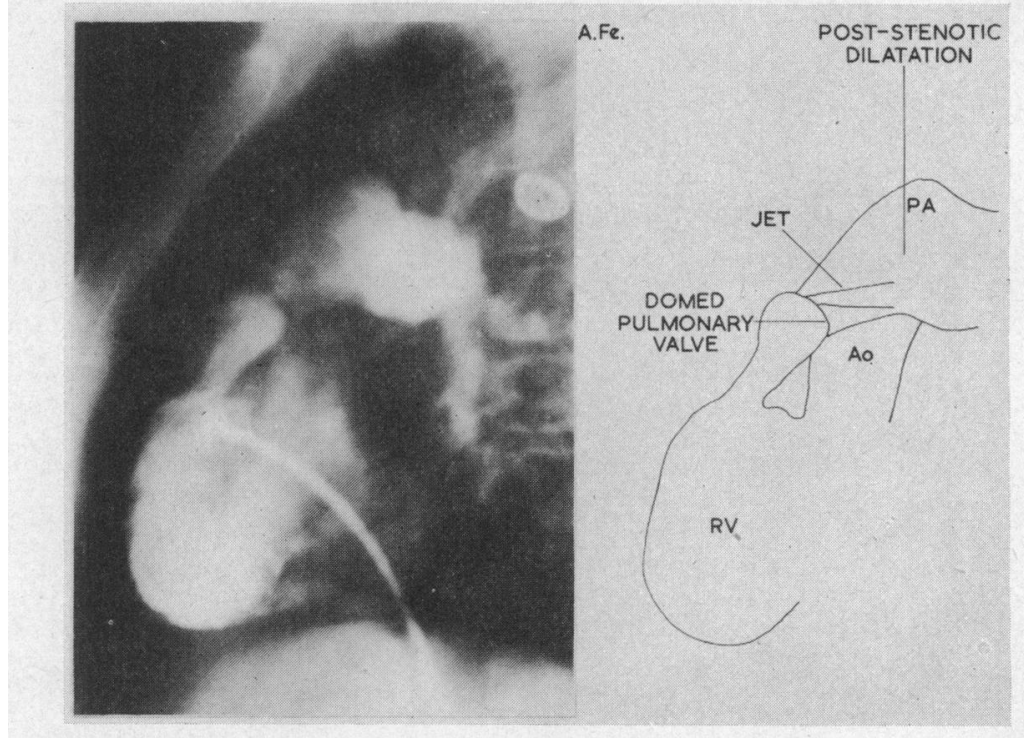

Fig. 3.-Lateral view, right ventricular injection. The domed pulmonary valve is clearly seen. A faint jet of contrast material is visible. Note post-stenotic dilatation of the pulmonary artery.

of patients with the tetralogy of Fallot the defect extends to the attachment of this cusp, and its position therefore acts as a valuable landmark to the postero-inferior limit of the ventricular septal defect.

The size of the defect was recorded as a simple measurement in centimetres, no attempt being made to correct differing sizes of patient and radiographic magnification factors.

The site of the ventricular septal defect was noted and its relation to the crista supraventricularis was studied.

Calibre of Aorta and Main Pulmonary Artery. The lateral projection was again used to determine the calibre of the aorta and main pulmonary artery. Systolic films were studied and the results from the angiocardiographic analysis therefore represent the maximum calibres of these vessels. The aortic calibre was measured at a point immediately distal to the sinuses of Valsalva, and the pulmonary artery calibre immediately distal to the pulmonary sinuses. The post-stenotic dilatation frequently seen in the pulmonary artery does not, therefore, influence the figures.

Right Ventricular Outflow Tract Obstruction. The presence or absence of pulmonary valve stenosis was determined by a study of both the antero-posterior and lateral projections. Doming of the pulmonary valve cusps in systole with or without the presence of a jet of contrast material was held to indicate pulmonary valve stenosis (Fig. 3). Decreased mobility of the valve alone was not considered to be a sound criterion for the diagnosis of valvar stenosis, for mobility of the cusps may be influenced to some extent by the volume of pulmonary blood flow. Thickening of the pulmonary valve cusps is frequently seen but when present as the sole abnormality was not held to be of diagnostic significance.

Infundibular stenosis was recorded as present or absent. When present, it was designated as either tubular or localized (Kjellberg et al., 1959). Examples of the two types are shown in Fig. 4A and B, the localized form of stenosis consisting of a relatively circumscribed area of obstruction associated with the formation of an infundibular chamber or third ventricle, as opposed to the tubular form with a diffuse area of obstruction and no formation of a significant infundibular chamber. Although differentiation between the two types is usually easy, occasional patients are seen in whom the obstruction takes on apparently intermediate forms and classification may be difficult. No satisfactory method could be found to quantitate the severity of either valvar or infundibular stenosis.

The size of the pulmonary valve ring was measured in those cases where the valve cusps were well enough outlined. The lateral projection was usually found best for this purpose.

Degree of Aortic Override. Aortic override is conventionally assessed in early lateral films when contrast material can be seen filling the aorta from the right ventricle (Kjellberg et al., 1959; Vogelpoel et al., 


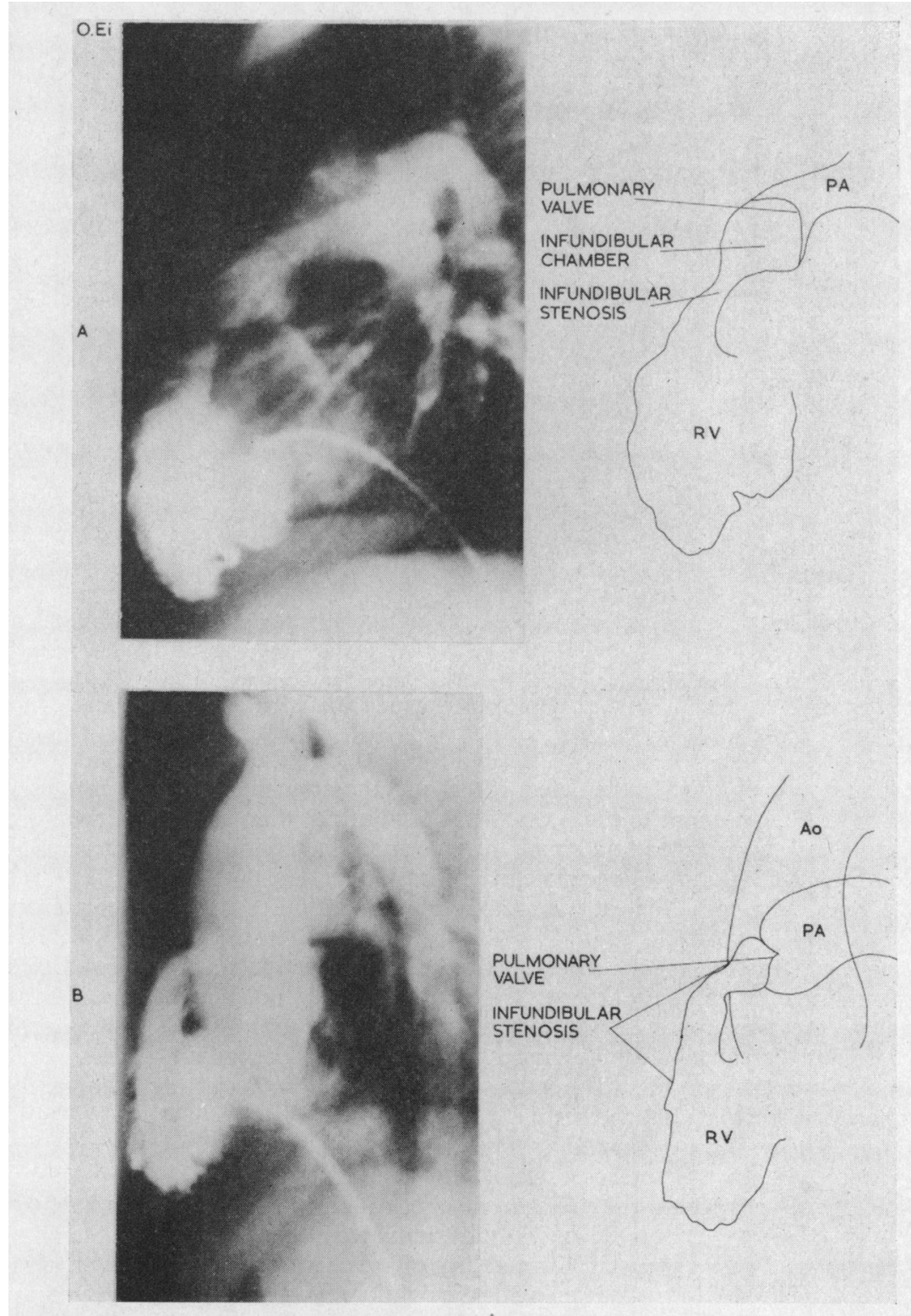

Fig. 4.-A. Lateral view, right ventricular injection. Localized type of infundibular stenosis with formation of a small infundibular chamber.

B. Lateral view, right ventricular injection. Tubular type of infundibular stenosis of severe degree. The small pulmonary valve ring, together with marked post-stenotic dilatation of the pulmonary artery are faintly visible through the very large aorta.

1957). Opacification of the aorta will occur, however, regardless of whether aortic override is present or not, and the stream of contrast material outlines the ventricular septal defect rather than the relation of the aortic root to the interventricular septum. The relation of the aorta to the pulmonary trunk may be equally misleading, for an apparently anterior position of the aorta may be due solely to the dilatation of this vessel commonly found in the tetralogy of Fallot. During the course of the present study it was noted that the interventricular septum may often be visualized directly in the later lateral films when contrast material has passed through the lungs and is filling the left ventricle and aorta. The enlargement of the right ventricle 


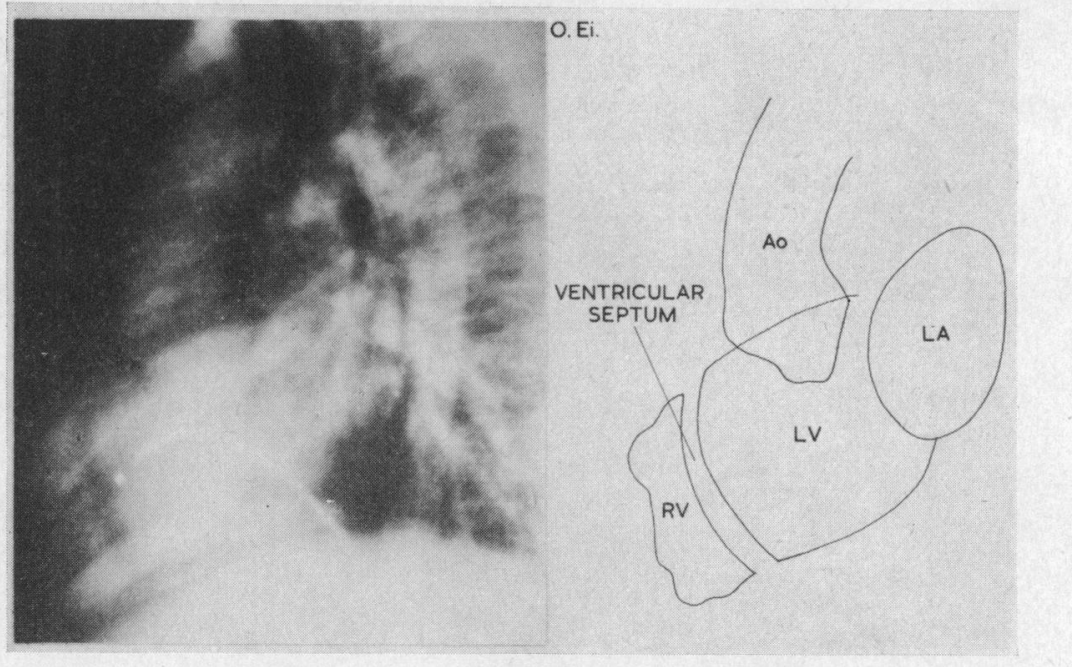

FIG. 5.-Late lateral film, right ventricular injection. Contrast has passed through the lungs and now opacifies the left ventricle and aorta. The ventricular septum can be seen second as a translucent area immediately anterior to the catheter tip. Note that aortic root is entirely posterior to the septum. The catheter appearing to lie in the left ventricle is an optical illusion.

in the tetralogy of Fallot tends to cause rotation of the heart with a backwards and upwards tilting of the apex. These changes, resulting in the typical "cour en sabot" appearances on chest radiograph, are useful in that the interventricular septum comes to lie in a frontal plane instead of its normally oblique position. The septum is thus displaced in a direction that may enable it to be seen "end-on" in angiocardiograms taken in the lateral projection (Fig. 5). When the septum is seen in this way it becomes a simple matter to assess its position with respect to the root of the aorta. A limitation of the method is that the septum may not be clearly shown in those patients with the severest degrees of right ventricular outflow tract obstruction, for in these circumstances, the pulmonary blood flow may be insufficient to allow enough contrast material to pass (as a bolus) through the lungs and opacify the left ventricle.

In the present study, aortic override was graded as nil if no portion of the aortic root appeared to lie anterior to the interventricular septum, 25 per cent if a portion of the anterior aortic sinus projected forwards of the septum, 50 per cent if half or all the sinus lay anteriorly (Fig. 6), and 75 per cent if more than the anterior sinus appeared forward. The condition where the whole of the aortic root lies anteriorly to the plane of the septum (category $100 \%$ ) would constitute the condition of double outlet right ventricle, and such cases have been excluded from this study.

Left Atrial Size. Various methods of assessing left atrial size were considered, including that of Arvidsson (1958), but in the tetralogy of Fallot the poor pulmonary flow commonly prevents adequate opacification of the left atrium throughout a sufficient number of cardiac cycles to enable this method to be used with any degree of accuracy. Considering these facts it was decided that the most practical method of assessment was simply to record one observer's impression of the left atrium as being of normal, small, or very small size. In making this assessment both antero-posterior and lateral projections were considered, and a large number of angiocardiograms of patients, in whom the left atrial size might be expected to be normal, were studied in order to familiarize the observer with the normal limits of variation in the dimensions of this chamber. By these means a reasonable, but not very accurate, record of left atrial size was obtained, but as in the method of assessing aortic override, pulmonary blood flow may be inadequate in some instances to produce satisfactory opacification of the chamber.

\section{RESULTS}

Ventricular Septal Defect. The limits of the ventricular septal defect could be defined in the angiocardiograms sufficiently to allow of measurement in 44 of the 50 patients. The size of the 


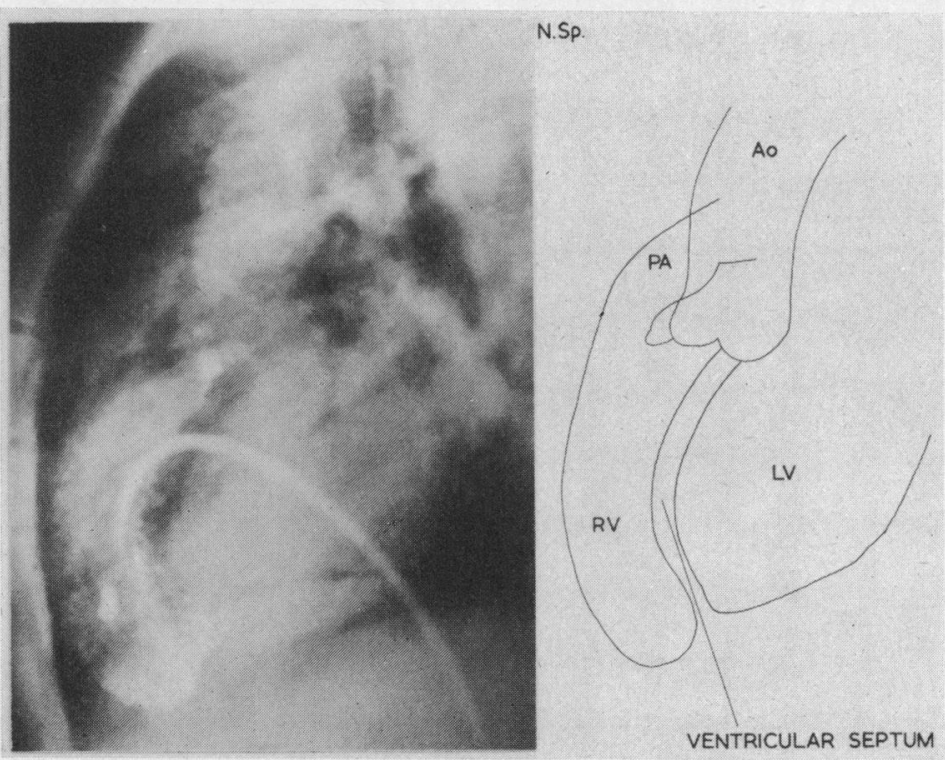

Fig. 6.-Late lateral film, right ventricular injection. Ventricular septum is seen as in Fig. 5, in this case aided by a small subendocardial extravasation of contrast material in the right ventricle. 75 per cent aortic override is present.

defect as assessed ranged from 1.2 to $4.0 \mathrm{~cm}$., with 27 of the 44 patients $(62 \%)$ falling in the 2.0 to $3.0 \mathrm{~cm}$. range.

A note of the size of the defect was available in 40 of the 44 patients operated on, and the measurement chosen for comparison was that of the long axis of the defect, i.e. along a cephalo-caudal plane. The ventricular septal defect in the tetralogy of Fallot is usually elliptical in shape but only the measurement of one dimension is possible from the angiocardiogram. The correlation between the surgical and radiological assessments is shown in Fig. 7. It will be seen that, in general, a fair agreement exists, there seeming a tendency for the size of the defect to be slightly underestimated from the angiocardiogram. Nevertheless in 35 of the patients $(88 \%)$ the assessments did not differ by more than $0.5 \mathrm{~cm}$. From the angiocardiograms, the ventricular septal defect was thought to be infracristal in all 50 patients, this being confirmed at operation in each instance.

Calibre of Aorta and Main Pulmonary Artery. The measurements obtained from the radiological analysis are expressed as the ratio of pulmonary artery calibre to aortic calibre. It was possible to derive a figure for this ratio from the angiocardiograms of all 50 patients. Measurements of the

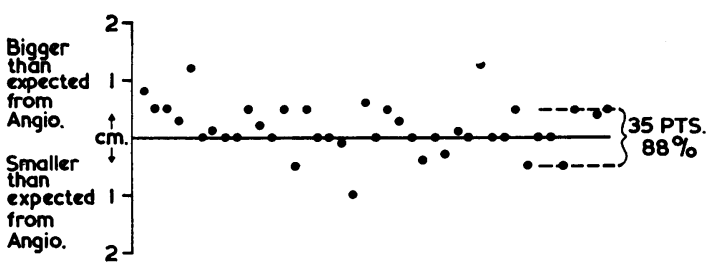

FIG. 7.-Deviation in size of ventricular septal defect (VSD) between angiographic and surgical estimates (see text).

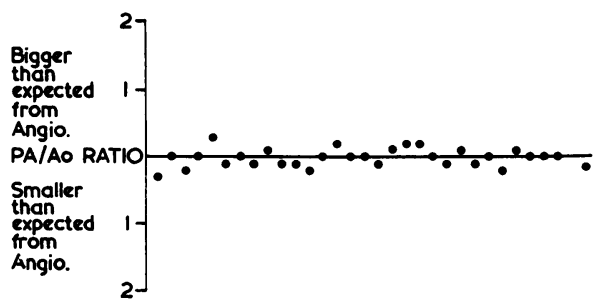

FIG. 8.-Deviation in pulmonary artery (PA) and aorta (Ao) ratio between angiographic and surgical estimates (see text). 
TABLE II

Right Ventricular Outflow Tract Obstruction

\begin{tabular}{|c|c|c|c|c|c|c|}
\hline & & & & & Present & Absent \\
\hline $\begin{array}{l}\text { 1. Pulmonary Valve Stenosis* } \\
\text { Angiographic assessment } \\
\text { Surgical assessment } \quad .\end{array}$ & 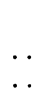 & $\therefore$ & $\because$. & $\because$. & $\begin{array}{l}41 \\
37\end{array}$ & $\begin{array}{r}9 \\
13\end{array}$ \\
\hline $\begin{array}{l}\text { 2. Pulmonary Infundibular Sten } \\
\text { Angiographic assessment } \\
\text { Surgical assessment } \quad \text {. }\end{array}$ & $\begin{array}{l}\dagger \\
\cdots \\
\cdots\end{array}$ & $\therefore$ & $\begin{array}{l}\cdots \\
\cdots\end{array}$ & $\begin{array}{l}\cdots \\
\cdots\end{array}$ & $\begin{array}{l}48 \\
48\end{array}$ & $\begin{array}{l}2 \\
2\end{array}$ \\
\hline
\end{tabular}

* Agreement between angiographic and surgical assessments in 42 of 50 patients.

† Agreement between angiographic and surgical assessments in all patients.

TABLE III

TYPE OF INFUNDIBULAR STENOSIS

\begin{tabular}{lll|c|c|c}
\hline & & & $\begin{array}{c}\text { Tubular } \\
\text { stenosis }\end{array}$ & $\begin{array}{c}\text { Localized } \\
\text { stenosis }\end{array}$ & Total \\
\cline { 1 - 5 } Angiographic assessment. & $\ldots$ & $\ldots$ & 16 & 32 & 48 \\
Surgical assessment $\quad$. & $\ldots$ & $\ldots$ & 12 & 34 & 46 \\
\hline
\end{tabular}

Agreement between angiographic and surgical assessments in 41 of 46 patients.

pulmonary artery/aorta ratio were taken during surgical correction in only 31 patients, but as might be expected there was an excellent correlation between the two sets of data (Fig. 8).

Right Ventricular Outflow Tract Obstruction. The correlation between radiological and surgical assessments of the presence of pulmonary valve and/or infundibular stenosis is shown in Table II. Whereas there is excellent agreement regarding infundibular stenosis, valvular stenosis appears to be over-diagnosed to some extent from angiocardiography. Two patients $(4 \%)$ were thought on both radiological and surgical grounds to have pulmonary valve stenosis only, and 13 patients $(26 \%)$ were thought at operation to have only infundibular stenosis. In the remaining patients $(70 \%)$ combined lesions were found. These figures show a considerable discrepancy from previous reports in which the incidence of solitary pulmonary valve stenosis has been stated to be between 22 and 35 per cent (Brock, 1957; Barnard and Schrire, 1961; Bailey, 1955).

From the surgical notes it was possible to determine the type of infundibular stenosis in 46 patients, and a differentiation could be made from the angiocardiogram in 48 . There was agreement between the two findings in 41 patients (Table III).

The size of the pulmonary valve ring was not routinely recorded at operation, and no complete comparison between surgical and radiological data is possible concerning this particular point. In the angiocardiograms the pulmonary valve cusps were visualized sufficiently well to allow measure ment of the pulmonary valve ring in 44 patients. In 7 of these the ring was less than $1.5 \mathrm{~cm}$., in 19 it was less than $2.0 \mathrm{~cm}$., and in 18 the diameter was more than $2.0 \mathrm{~cm}$. A suggestive correlation was noted between a small pulmonary valve ring and the tubular type of infundibular stenosis (Table IV).

When assessing the size of the pulmonary valve ring in Fallot's tetralogy attention should be drawn to a possible error of interpretation. In this variety of cyanotic heart disease the doming of the pulmonary valve cusps may be associated with considerable elongation of the cusp tissue itself, resulting in displacement of the valve orifice distally within the lumen of the pulmonary artery for an appreciable distance. If this process occurs to an extent whereby the valve orifice comes to lie in a segment of the pulmonary artery affected by post-stenotic dilatation, the post-stenotic segment 
TABLE IV

Size of Pulmonary Valve Ring and Type of Infundibular Stenosis

\begin{tabular}{|c|c|c|c|c|c|c|c|}
\hline \multirow{2}{*}{\multicolumn{3}{|c|}{ Size of valve ring }} & \multicolumn{2}{|c|}{ Tubular stenosis } & \multicolumn{2}{|c|}{ Localized stenosis } & \multirow{2}{*}{ Total } \\
\hline & & & No. & Per cent & No. & Per cent & \\
\hline $\begin{array}{l}1.5 \mathrm{~cm} \text {. or less } \\
2.0 \mathrm{~cm} \text {. or less } \\
>2.0 \mathrm{~cm} .\end{array}$ & $\begin{array}{l}. . \\
\cdots \\
\cdots\end{array}$ & $\begin{array}{l}\ldots \\
\cdots \\
\ldots\end{array}$ & $\begin{array}{l}5 \\
8 \\
2\end{array}$ & $\begin{array}{l}72 \\
42 \\
11\end{array}$ & $\begin{array}{r}2 \\
11 \\
16\end{array}$ & $\begin{array}{l}28 \\
58 \\
89\end{array}$ & $\begin{array}{r}7 \\
19 \\
18\end{array}$ \\
\hline
\end{tabular}

of the pulmonary artery may be misinterpreted as an infundibular chamber and the illusion created of a wide pulmonary valve ring. The true pulmonary valve ring is then usually thought to be a localized infundibular narrowing, the ring, in fact, commonly being considerably smaller than normal under these circumstances. The error is best avoided by a careful study of the pulmonary valve cusps throughout as many phases of systole as possible, the elongation of the cusp tissue usually then becoming apparent at some stage (Fig. 9A and B).

Aortic Override. Only scanty data were available from the surgical notes regarding aortic override, the lack of detailed information being such as to discount any attempt to grade the severity of the override. In those patients where comments such as "severe" were made concerning aortic override, there appeared to be little correlation with the findings of the angiocardiographic analysis. This discrepancy is not surprising when the limitations of a retrospective study are considered, and the surgeon's difficulties in making an accurate assessment of the position of the aortic root in the
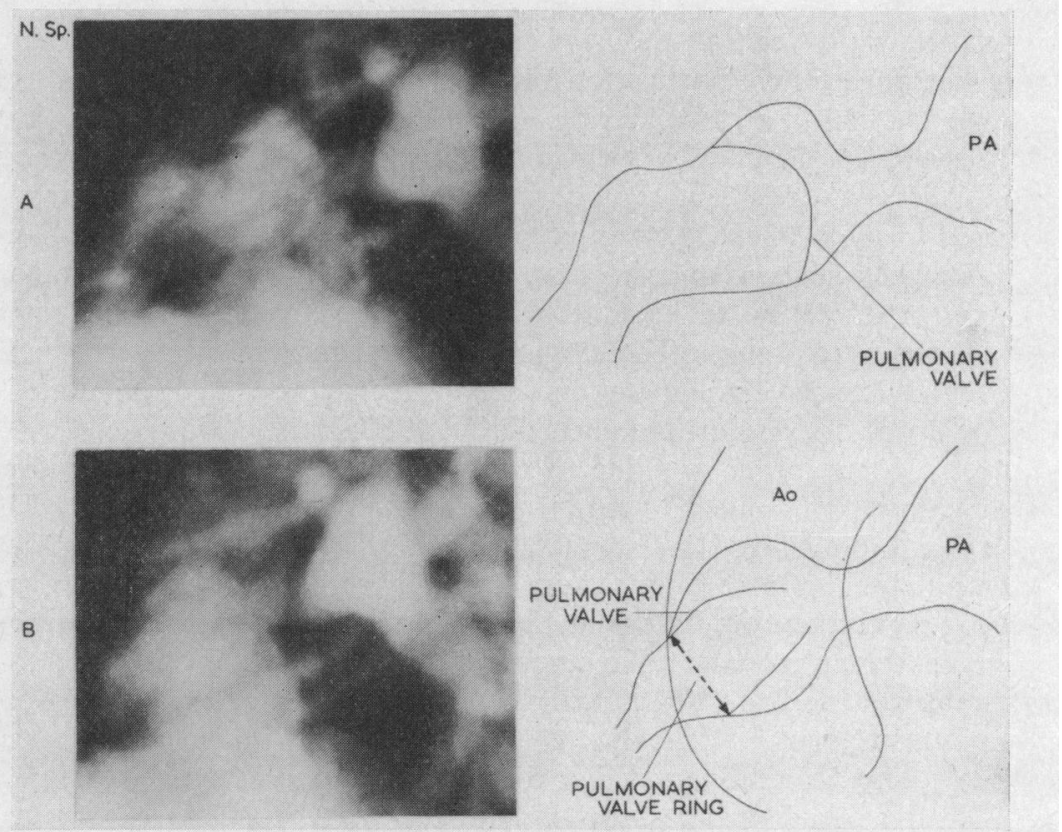

FIG. 9.-A. Lateral view, right ventricular injection. Elongation of pulmonary cusps. The domed pulmonary valve is clearly seen and the cusps appear of normal length. The pulmonary valve ring could be taken to lie at the point where the cusps appear to merge with the wall of the pulmonary artery. This is fallacious.

B. Same patient, one frame later. Systole has advanced and contrast material has appeared in the aorta. It is now apparent that the pulmonary valve cusps are elongated and the pulmonary valve ring is, in fact, quite small. 
presence of a large ventricular septal defect, possible aortic reflux, and the disturbances of normal anatomy occasioned by open-heart surgery are taken into account.

Angiographic assessment of the degree of aortic override was possible in 42 patients. No override was thought present in 14 patients; there was 25 per cent override in 19, and 50 per cent in 9.

Left Atrial Size. The size of the left atrium could be assessed from the angiocardiogram in the manner previously described in 35 of the 50 patients. Although both projections were considered for this purpose, the lateral view was generally the most informative. The chamber was thought to be normal in 10 , small in 12 , and very small in 13 patients. No data were obtainable in 15 patients. In 10 of these the angiocardiographic programme was not sufficiently prolonged to allow transit of the contrast material through the lungs, and opacification of the left atrium was thus not seen. In the remaining 5 patients contrast material appeared to be filling the pulmonary veins but the left atrium did not opacify sufficiently to allow assessment of its size. These patients presumably had an extremely poor pulmonary blood flow.

No assessment of left atrial size was made at operation in any of the patients under study, though in a certain number measurements of the left atrial pressure had been carried out on the operating table. Objective confirmation of the validity of the angiocardiographic assessment of left atrial size is, therefore, lacking.

\section{Discussion}

Since the angiocardiographic interpretations had a reasonable correlation with the subsequent surgical findings, when both assessments were available for comparison, the further aim of this study was to attempt to determine whether any of the angiocardiographic information would be relevant to the technique and prognosis of surgical management in the future.

Ventricular Septal Defect. It has been shown that in the majority of patients with the tetralogy of Fallot, a good selective right ventricular angiocardiogram provides a satisfactory method of assessing the size of the ventricular septal defect, bearing in mind that the defect is probably in the region of $0.5 \mathrm{~cm}$. larger than the radiological appearances suggest. The examination does not, however, give any information regarding the exact relation of the defect to the septal cusp of the tricuspid valve, and in particular, whether any abnormalities of the septal cusp are present, such as a cleft or adherence of the cusp tissue to the defect.

Within broad limits the size of the ventricular septal defect is of little practical importance, for with the use of prosthetic materials large defects can be successfully closed. The presence of a virtually common ventricle, however, does lead to considerable surgical difficulties and the main importance of delineating the limits of the defect is to exclude a common ventricle or a very large defect with minimal septal remnants. If the limits of the defect cannot be defined from a study of the right ventricular angiocardiogram it seems wise to proceed to left ventricular angiography in order that the maximum information can be made available.

No relation could be found between the size of the ventricular septal defect and the occurrence of complete heart block following surgery. No correlation appeared to exist between the size of the defect and the degree of aortic override as assessed from the angiocardiogram. It had been thought that with the bigger defects the largely unsupported aortic root might tend to lie more anteriorly than in the case of a small defect, but this thesis could not be substantiated from the available evidence. Nevertheless, a trend of this nature might be revealed by a larger series.

The site of the ventricular septal defect could be determined without difficulty in the present series, all patients proving to have the infracristal type usual in Fallot's tetralogy. Subsequently, however, we have seen three examples of the "bulboventricular" type of defect. In this lesion an extremely large deficiency in the ventricular septum is associated with an absence of the normally well-developed crista supraventricularis. The ventricular septal defect may extend upwards to the pulmonary valve ring, with the dilated aorta presenting into the defect. As significant infundibular stenosis does not occur due to the failure of development of the crista supraventricularis, such 
patients, if cyanosed, have severe valvar pulmonary stenosis, usually with a very small pulmonary valve ring. An example of this type of defect is shown in Fig. 10A. Experience has shown that surgical correction presents more formidable difficulties than is usual. It is believed that angiocardiography offers the best way of detecting these particular defects if a careful study of the crista supraventricularis is made. In the usual form of the tetralogy of Fallot, the crista is seen without difficulty in either the antero-posterior or lateral projection (Fig. 10B) in contrast to the bulboventricular type of defect, where cristal development is lacking.

Calibre of the Aorta and Main Pulmonary Artery. The good correlation between the pulmonary artery/aorta ratio as assessed by angiocardiography and that found at operation has previously been stated. Fig. 11 illustrates the findings when this ratio is plotted against operative mortality. It appears that the smaller values of pulmonary artery/aorta ratio are associated with an increased 
operative mortality, but this statement must be regarded with great caution. The total numbers of patients are not large, and any comment concerning operative mortality in Fallot's tetralogy must be tempered by an awareness of the multiple factors involved which may cause death. Improved techniques and changing surgical methods may modify the higher mortality usually found shortly after the introduction of a new operation and may easily lead to false impressions concerning the cause of operative death. The apparent correlation between operative mortality and the

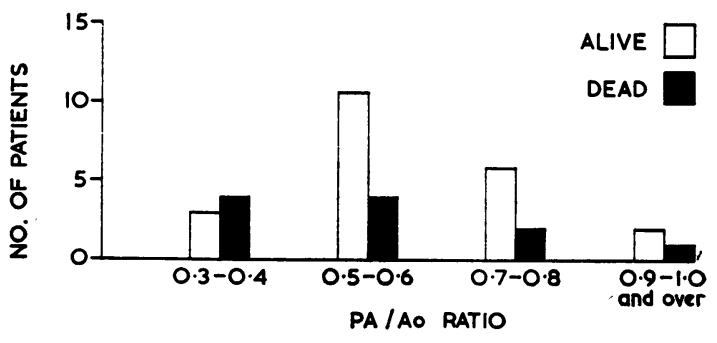

FIG. 11.-Surgical estimate of pulmonary artery (PA) and aortic (Ao) ratio related to mortality. pulmonary artery/aorta ratio should, therefore, be seen in the light of Table $\mathrm{V}$ which illustrates the improvement in surgical results in the 50 patients as the passage of time has brought greater experience and better techniques.

TABLE $\mathrm{V}$

Operative Mortality in 50 Patients Under Study

\begin{tabular}{|c|c|c|c|c|c|}
\hline & & & & \multicolumn{2}{|c|}{ Date of operation } \\
\hline & & & & July 1958-April 1961 & April 1961-July 1963 \\
\hline \multirow[t]{2}{*}{$\begin{array}{l}\text { Alive } \\
\text { Dead }\end{array}$} & $\begin{array}{l}. . \\
. .\end{array}$ & $\begin{array}{l}. . \\
.\end{array}$ & . & $\begin{array}{l}7 \\
6\end{array}$ & $\begin{array}{r}28 \\
9\end{array}$ \\
\hline & Total & .. & .. & 13 & 37 \\
\hline
\end{tabular}

Type of Infundibular Stenosis, Size of Pulmonary Valve Ring, and Left Atrial Size. It has already been noted that the tubular type of infundibular stenosis tends to be associated with a small pulmonary valve ring. The apparent relationships between the type of infundibular stenosis, the size of the pulmonary valve ring, and the left atrial size, and the crude operative mortality are shown in Tables VI and VII. The comments made regarding the pulmonary artery/aorta ratio are equally relevant in this context.

Degree of Aortic Override. There was no relation demonstrable between the degree of aortic override and operative mortality. Nevertheless, assessment of aortic override in the manner previously described seems to be valuable as a means of detecting the most severe degrees of override and also the presence of a double outlet right ventricle, both circumstances in which the difficulties of corrective surgery are greatly increased.

Significance of Results. The qualifications that must be remembered when considering apparent correlations between the anatomy of the Fallot's tetralogy and subsequent operative mortality have already been discussed, but the features suggested as possibly being of bad prognostic significance, namely the tubular type of infundibular stenosis, a small pulmonary valve ring, a small left atrium, and a small pulmonary artery/aorta ratio, are all findings connected with a particularly poor pulmonary blood flow.

In addition to increasing the technical difficulties of relieving outflow tract obstruction, these factors indicate the probable necessity for an outflow tract prosthesis with the concomitant risk of pulmonary incompetence, and an as yet unknown long-term morbidity.

A severely impaired pulmonary blood flow would be expected to be associated with a greater disturbance of physiology, and factors other than the cyanosis and polycythæmia already known to increase the hazard of complete correction (Kirklin et al., 1960) may ultimately prove extremely relevant to the surgical prognosis of this disease. The relation between a poor pulmonary blood 
TABLE VI

A: Type of Infundibular Stenosis and Operative Mortality

\begin{tabular}{llllll|l}
\hline \multicolumn{5}{c|}{ Type of stenosis } & & Deaths \\
\hline Tubular (16 patients) &. &. &. &. &. & $7(44 \%)$ \\
Localized (32 patients) &.. &. &.. &. &.. & $8(25 \%)$ \\
\hline
\end{tabular}

B: Size of Pulmonary Valve Ring and Operative Mortality

\begin{tabular}{|c|c|c|c|}
\hline Size of $v$ & ring & & Deaths \\
\hline $\begin{array}{l}1.5 \mathrm{~cm} . \text { or less }(7 \text { patients }) . . \\
2.0 \mathrm{~cm} \text {. or less }(19 \text { patients }) \\
>2.0 \mathrm{~cm} .(18 \text { patients })\end{array}$ & $\begin{array}{ll}. & \ldots \\
. & \ldots \\
. . & \cdots\end{array}$ & $\begin{array}{l}\cdots \\
\cdots \\
\cdots\end{array}$ & $\begin{array}{l}4(57 \%) \\
6(32 \%) \\
3(17 \%)\end{array}$ \\
\hline
\end{tabular}

TABLE VII

Left Atrial Size and Operative Mortality in 35 Patients

\begin{tabular}{|c|c|c|c|c|c|c|}
\hline \multicolumn{5}{|c|}{ L.A. size } & \multirow{2}{*}{$\begin{array}{c}\text { Alive } \\
\begin{array}{r}9 \\
11 \\
5\end{array}\end{array}$} & \multirow{2}{*}{$\begin{array}{c}\text { Dead } \\
1 \\
1 \\
8\end{array}$} \\
\hline $\begin{array}{l}\text { Normal } \\
\text { Small } \\
\text { Very small }\end{array}$ & $\begin{array}{l}\ldots \\
\cdots \\
\ldots\end{array}$ & $\begin{array}{l}\ldots \\
\cdots \\
\cdots\end{array}$ & $\begin{array}{l}\cdots \\
\cdots \\
\cdots\end{array}$ & $\begin{array}{l}\ldots \\
\cdots \\
\ldots\end{array}$ & & \\
\hline
\end{tabular}

flow and the "pulmonary post-perfusion syndrome" are inadequately understood at the present time, but likely to be of great importance in the management of the tetralogy.

Attempts to break down the crude figures for operative mortality according to the precipitating cause of death are of little value, for the interplay of multiple factors makes a clear analysis difficult in many instances, and the relatively small number of patients minimizes the importance of any one factor. Nevertheless, as long as a significant mortality is associated with complete correction of the tetralogy of Fallot, the responsibility of the physician is to inquire into features of possible prognostic importance.

\section{SUMMARY}

The selective right ventricular angiocardiograms of 50 patients with Fallot's tetralogy were analysed with regard to the site and size of the ventricular septal defect, the calibre of the main pulmonary artery and aorta, the presence and nature of right ventricular outflow tract obstruction, the size of the pulmonary valve ring, the degree of aortic override, and the size of the left atrium. The data thus obtained have been compared with the findings noted by the surgeon at the time of subsequent complete correction.

There was a good correlation between the radiological and surgical assessments of the site and size of the ventricular septal defect, the tendency being for the angiocardiogram to underestimate defect size by about $0.5 \mathrm{~cm}$. Attention is drawn to the bulbo-ventricular type of defect where a large deficiency in the ventricular septum is associated with a failure in development of the crista supraventricularis.

A method is described of assessing the degree of aortic override by visualization of the ventricular septum and its relation to the aortic root in late lateral angiocardiographic films. The possible sources of error in the assessment of the size of the pulmonary valve ring are discussed, and reference made to the syndrome of "cusp elongation" in the tetralogy of Fallot.

Infundibular stenosis has been assessed as either tubular or localized, the tubular type being 
more frequently associated with a small pulmonary valve ring. A good agreement has been found between radiological and surgical assessments of the various features studied, those either due to, or causing, a poor pulmonary blood flow appearing to be linked to higher operative mortality when this is expressed as a crude figure. The influence of changing operative techniques and greater experience make the interpretation of these findings difficult, but it is suggested that, at least until greater experience has been obtained, a small calibre pulmonary artery, a small pulmonary valve ring, a small left atrium, and the presence of the tubular type of infundibular stenosis should all be regarded as unfavourable prognostic features as regards the outcome of an operation for complete correction of the tetralogy of Fallot.

The authors are greatly indebted to Professor J. F. Goodwin, Professor R. E. Steiner, Mr. W. P. Cleland, Mr. H. H. Bentall, and Dr. C. M. Oakley for their valuable criticism and advice throughout the period in which this study was undertaken. We are grateful to Mr. G. Rainbow and the staff of the Angiocardiography unit for their co-operation and assistance, and thank Mrs. A. Cartwright, Miss A. Sweetland, and the Departments of Photography and Medical Illustration for their help in the preparation of this paper.

\section{REFERENCES}

Arvidsson, H. (1958). Angiographic observations in mitral disease; with special reference to volume variations in the left atrium. Acta. radiol. (Stockh.), Suppl. 158.

Bahnson, H. T., Spencer, F. C., Landtman, B., Wolf, M. D., Neill, C. A., and Taussig, H. B. (1962). Surgical treatment and follow-up of 147 cases of tetralogy of Fallot treated by correction. J. thorac. cardiovasc. Surg., 44, 419.

Bailey, C. P. (1955). Surgery of the Heart. Lea and Febiger, Philadelphia.

Barnard, C. N., and Schrire, V. (1961). The surgical treatment of the tetralogy of Fallot. Thorax, $16,346$.

Bristow, J. D., Menashe, V. D., Griswold, H. E., and Starr, A. (1961). Total correction of tetralogy of Fallotcomplications and results. Amer. J. Cardiol., 8, 358.

Brock, R. C. (1957). The Anatomy of Congenital Pulmonary Stenosis. Cassell, London.

Coelho, E., de Paiva, E., de Pádua, F., Nunes, A., Amram, S., Bordalo e Sá, and Luis, S. (1961). Tetralogy of Fallot. Angiocardiographic, electrocardiographic, vectorcardiographic and hemodynamic studies of the Fallot-type complex. Amer. J. Cardiol., 7, 538.

Gerbode, F., Johnston, J. B., Sader, A. A., Kerth, W. J., and Osborn, J. J. (1961). Complete correction of the tetralogy of Fallot. Arch. Surg., 82, 793.

Kay, E. B., Nogueira, C., Mendelsohn, D., Jr., and Zimmerman, H. A. (1961). Corrective surgery for tetralogy of Fallot. Evaluation of results. Circulation, 24, 1342.

Keith, J. D., Rowe, R. D., and Vlad, P. (1958). Heart Disease in Infancy and Childhood. Macmillan, New York.

Kirklin, J. W., Payne, W. S., Theye, R. A., and DuShane, J. W. (1960). Factors affecting survival after open operation for tetralogy of Fallot. Ann. Surg., 152, 485.

Kjellberg, S. R., Mannheimer, E., Rudhe, U., and Jonsson, B. (1959). Diagnosis of Congenital Heart Disease, 2nd ed. Year Book Publishers, Chicago.

Lillehei, C. W., Cohen, M., Warden, H. E., Read, R. C., Aust, J. B., DeWall, R. A., and Varco, R. L. (1955). Direct vision intracardiac surgical correction of the tetralogy of Fallot, pentalogy of Fallot, and pulmonary atresia defects: Report of first ten cases. Ann. Surg., 142, 418.

Malm, J. R., Bowman, F. O., Jr., Jameson, A. G., Ellis, K., Griffiths, S. P., and Blumenthal, S. (1963). An evaluation of total correction of tetralogy of Fallot. Circulation, 27, 805.

Morgan, J., Pitman, R., Goodwin, J. F., Steiner, R. E., and Hollman, A. (1962). Anomalies of the aorta and pulmonary arteries complicating ventricular septal defect. Brit. Heart J., 24, 279.

Neufeld, H. N., DuShane, J. W., and Edwards, J. E. (1961). Origin of both great vessels from the right ventricle. II. With pulmonary stenosis. Circulation, 23, 603.

Robertson, R., Ashmore, P. G., Allen, P., and Leach, W. B. (1962). Surgical treatment of tetralogy of Fallot. J. thorac. cardiovasc. Surg., 43, 343.

Senning, A. (1959). Surgical treatment of right ventricular outflow tract stenosis combined with ventricular septal defect and right-left shunt. ("Fallot's tetralogy"). Acta chir. scand., 117, 73.

Vogelpoel, L., Schrire, V., Nellen, M., and Goetz, R. H. (1957). The differentiation of the tetralogy of Fallot from severe pulmonary stenosis with intact ventricular septum and right-to-left interatrial shunt. Angiology, 8, 215.

Wood, P. (1956). Diseases of the Heart and Circulation, 2nd ed. Eyre and Spottiswoode, London. 